TP Periodica Polytechnica

Social and Management

Sciences

24(2), pp. 102-112, 2016

DOI: $10.3311 /$ PPso. 8436

Creative Commons Attribution (i)

RESEARCH ARTICLE

\section{Different Approaches to Fraud Risk Assessment and Their Implications on Audit Planning}

\author{
Judit Fortvingler ${ }^{1,2}$, László Szívós ${ }^{1 *}$
}

Received 24 July 2015; accepted after revision 18 August 2015

\begin{abstract}
As a result of financial scandals, fraud has become an important concern over the past decades, which has also raised the issue of independent auditors' responsibilities for detecting fraud. This study examines how auditors perform fraud risk assessment by applying either the traditional or the decomposition methods to different perceived risk level settings. We also investigate how the outcomes of risk assessment influence the audit planning phase.

The results prove that the decomposition approach more significantly enhances auditors' sensitivity to fraud cues between a high and low fraud risk condition than using the traditional audit risk model. In addition, the perception of a more enhanced fraud risk leads to higher propensity to consult with forensic experts. Finally, the research also indicates that the assessed fraud risk level has fundamental impact on total hours budgeted for the audit engagement along with internal structure of total hours allocated to the audit.
\end{abstract}

\section{Keywords}

fraud risk assessment, decomposition method, forensic expert, audit planning

\footnotetext{
${ }^{1}$ Department of Finance, Faculty of Economic and Social Sciences, Budapest University of Technology and Economics

H-1117 Budapest, Magyar tudósok körútja 2., Hungary

${ }^{2}$ Department of Finance and Accounting, International Business School,

H-1031 Budapest, Záhony utca 7., Hungary

*Corresponding author, e-mail: szivos@finance.bme.hu
}

\section{Introduction}

The renowned accounting malfeasances of the past decades have raised the question to what extent users of financial information can be convinced that those truly and fairly represent the financial position and performance of a company. The scandals of Enron, WorldCom, and AIG are examples how fraud itself can deteriorate the trust in financial statements disclosed. In addition, as a secondary impact, some aspects of auditing had to be reconsidered all over the world. Fraud has been an important concern even in Hungary, provoked by recent collapses of some brokerage firms (Buda-Cash Zrt., Questor Zrt.), which has a serious social and economic effect on other sectors as well. Examining the patterns of such financial scandals, one can conclude that all directed the attention to the accountability of independent auditors in terms of material misstatements due to fraud; are they responsible for and capable of detecting fraud in all circumstances? How does the suspicion of fraud affect the nature of audit procedures to be performed?

From auditors' point of view, the rational approach to answer the aforementioned questions requires the profound understanding what professional auditing standards comprise regarding the terms and signals of fraud, and also the responses to the assessed risks of material misstatement due to fraud. Regardless the place in the world where an independent auditor performs audit services, one shall conform to generally accepted professional standards while conducting or participating in audit engagements. In the context of this research, two auditing frameworks are of crucial importance: on the one hand, the International Standards on Auditing (ISAs) released by the International Auditing and Assurance Standards Board (IAASB) and, on the other hand, the so-called Statements on Auditing Standards (SASs) issued by the Auditing Standards Board (ASB) of the American Institute of Certified Public Accountants (AICPA). The rationale behind this is twofold: our research concept is based on a study carried out in the U.S. where auditors shall comply with the standards issued by the ASB, while ISAs are mandatory for statutory audits in Europe proclaimed by the Directive 2014/56/EU of the European Parliament and of the Council of 16 April 2014 amending 
Directive 2006/43/EC on statutory audits of annual accounts and consolidated accounts.

In 2007, the ASB launched a clarity project in order to form standards that are easier to comprehend and apply, with remarkable efforts to converge its standards with ISAs. As a result, clarified SASs are different from the parallel ISAs only to a smaller extent where persuasive explanations exist (AICPA, 2014). The applicable fraud-related standards were deeply investigated in order to reveal if any differences had implications on our research process. We conclude that minor dissimilarities we found between ISAs and SASs (hereinafter Standards) do not impose limitations on our findings.

As laid down in the Standards, the suspect of fraud shall be taken into consideration in the whole process of auditing (Fig. 1).

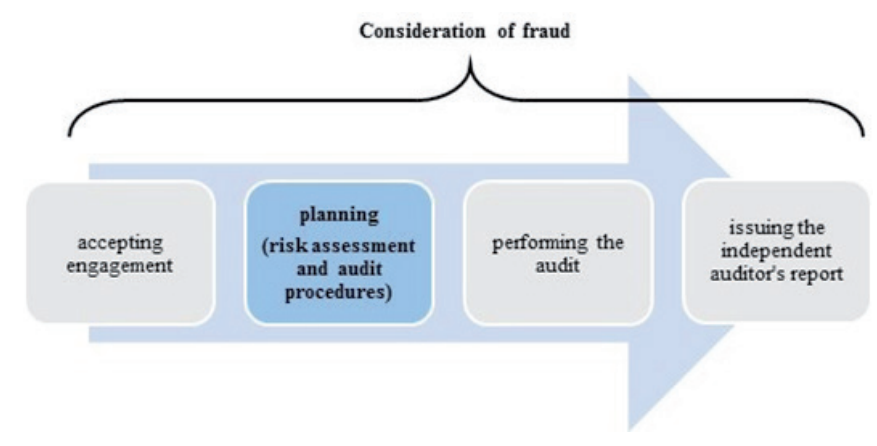

Fig. 1 Consideration of fraud in the audit process

This study focuses on the second step: the planning of audit. Out of the planning tasks, the risk assessment in terms of fraud, and its implication on the audit procedures are investigated by applying and contrasting two different approaches. Our research examines how different approaches of risk assessment (traditional vs. decomposition methods) influence the perceived level of fraud risk under different risk scenarios.

In the planning stage of an audit engagement auditors are expected to assess the components of the audit risk (i.e. inherent risk, control risk, and detection risk) with the traditional audit risk model required by the prevailing standards and then evaluate fraud risk separately. The audit risk formula given:

$$
A R=I R * C R * D R,
$$

where:

$\begin{array}{lll}\mathrm{AR} & = & \text { Audit Risk } \\ \mathrm{IR} & = & \text { Inherent Risk } \\ \mathrm{CR} & = & \text { Control Risk } \\ \mathrm{DR} & = & \text { Detection Risk. }\end{array}$

In the decomposition fraud risk assessment method, besides the traditional audit risk assessment model, the fraud risk is broken down into sub elements of the fraud triangle; the risk of incentives or pressure, the risk of rationalization or attitude, and finally the risk of opportunities to commit fraud (Wilks and Zimbelman, 2004; Favere-Marchesi, 2013).
Srivastava et al. (2009) proposed a further consideration in addition to the three previously mentioned components of the fraud triangle. The authors recommended to incorporate a forth risk factor, the risk that fraud specific procedures performed by auditors will fail to detect fraud, into the model. These four components together will draw the attention of auditors not only to fraud cues, the risks arising along the elements of the fraud triangle, but also to the risk that audit plan might contain ineffective fraud detecting procedures. The function of the aforementioned four factors represents the overall fraud risk:

$$
F R=R I * R A^{*} R O * R S P,
$$

where:

$\begin{array}{lll}\text { FR } & = & \text { Fraud Risk } \\ \text { RI } & = & \text { Risk of Incentives } \\ \text { RA } & = & \text { Risk of Attitude } \\ \text { RO } & = & \text { Risk of Opportunities } \\ \text { RSP } & \text { Risk that Special Procedures fail to detect }\end{array}$

fraud.

In addition to the examination of the impacts of the aforementioned two approaches on risk assessment, it is also explored how the fraud risk assessment affects the auditing procedures to be implemented by the auditor. From a research standpoint, it is essential to overview to what extent and how Standards support auditors' work as far as it is relevant to our research.

The Standards describe characteristics of fraud as misstatements in financial statements generated by an intentional action, involving either misappropriation of assets or fraudulent financial reporting (ISA 240 on 'The auditor's responsibilities relating to fraud in an audit of financial statements'). Fraud itself contains three elements; 1) incentive (or pressure) to achieve a target, 2) opportunity to commit a fraud, and 3 ) rationalization (or attitude) to do so, together widely-known as 'fraud triangle' in the academic literature (Cressey, 1973). The perception and assessment of the three elements is a key dimension of the research as fraud risk related researches define fraud as the function of these three determining factors influencing the behavior of a potential fraudster. Incentive is the perceived motivation or pressure on individual to commit fraud. Such incentive can be the pressure to achieve analysts' forecasts in the case of a listed company, or the motivation to pursue accounting profit which comes from large profit related bonus compensations. The opportunity arises when certain conditions facilitating the perpetration of fraud are in place. The lack or weaknesses of proper internal control might allow the misappropriation of assets. Inappropriate board structure or weak oversight might also facilitate the manipulation of accounting records in order to report higher earnings. Through the attitude, a person can rationalize the act itself. Each of the aforementioned factors are necessary but not sufficient conditions for committing fraud, so fraud risk assessment should consider the interaction of these factors (Loebbecke et al., 1989). 
With regards to the responsibility of the auditor, reasonable assurance shall be obtained that the financial statements are free from material misstatements, whether caused by fraud or error. Consequently, professional skepticism should be maintained to suspect or to identify the occurrence of fraud, and the necessity of continuous consideration of fraud is beyond dispute.

Based on the auditor's risk assessment, appropriate responses to the assessed risks of material misstatement caused by fraud shall be determined. The procedures shall reflect the fact that the auditor perceives higher risk of fraud. The Standards provide broad guidance in terms of fraud risk factors based on the elements of the fraud triangle, possible procedures to address the fraud risk, and depict circumstances that tend to indicate the occurrence of fraud. The expertise of professional Standards, reinforced by extensive audit experience and appropriate training, all fundamentally contribute to the ability of performing audit engagements of high quality in general, and from the aspect of fraud particularly.

\section{Literature review}

Zimbelman (1997) tested 108 auditors with a computer based case study and found that those auditors who were asked to assess fraud risk separately (intentional and unintentional misstatements) spent more time with reading red-flag cues compared to those who used the holistic method ${ }^{1}$. The research supported the hypothesis that the time taken to collect the necessary information from the case was mainly determined by the pursued risk assessment methodology. It was also evidenced that auditors using the decomposition method of risk assessment were more sensitive to fraud risk and, as a response, increased number of hours were budgeted for the higher fraud risk case. The study also addressed how auditors respond if higher fraud risk is perceived. The author found that there were no qualitative differences in responses, for which three possible reasons can be brought. Either (1) auditors do not have the professional and technical knowledge how to adjust audit plan with fraud specific procedures, or (2) auditors generally think it is not effective to adjust the audit plan, or (3) they do not believe that this adjustments is necessary.

Knapp and Knapp (2001) in their study examined the impact of professional experience on the ability of auditors to apply analytical procedures to detect fraud. The authors' research proved that more extensive experience will positively affect auditors' performance in detecting fraud. Audit managers were significantly more effective in assessing the risk of financial statement fraud with analytical procedures than were audit seniors. The authors also found that if auditors are provided with

1 The term of "holistic method" was later replaced by "traditional approach" to risk assessment by several academics. Within the framework of this study, we use also the expression of 'traditional'. Details of both the traditional and the decomposition approaches are elaborated in the Introduction section. explicit fraud risk assessment instructions they assess the risk of fraud consistently and significantly higher for the fraud case than without these instructions. In the lack of explicit fraud risk assessment, however, auditors did not assess significantly different fraud risk for the fraud case than for the non-fraud case. The study concluded that the combination of higher professional experience and explicit fraud risk assessment instructions brought more effective fraud risk assessment.

The effectiveness of using checklists in the risk assessment process and fraud detection responses was tested by Asare and Wright (2004). Standard risk checklists are frequently used in practice where risk factors are usually broken down into three categories recommended by AICPA (AU-C Sec. 240 on 'Consideration of Fraud in a Financial Statement Audit'). The experiment conducted supported their hypothesis that auditors in a no-checklist condition assess higher fraud risk than in a standard checklist condition. It was also revealed by the experiment that higher fraud risk assessment was not associated with more effective audit program plan, which means that audit program plans were not adjusted appropriately to reflect the measured fraud risk. Auditors without a standard audit program prepared a more effective set of fraud related tests and were more likely to consult with a fraud expert than those with a standard program. Authors also found that there is a positive association between fraud risk assessment and the auditors' intention to consult with fraud professionals.

A quite early research (Shelton, 2001) found that auditors may focus too much on the attitude component of the fraud triangle while tend to neglect the two others. As it was presented previously, the risk of fraud cannot be exclusively explained by the attitude of management, but it is a function of attitude, opportunity, and incentive. Several common sense explanations can be brought up to support this previous idea. On the one hand, the decomposition of fraud risk might reveal information which may be overlooked in the holistic case. On the other hand, the decomposition approach requires less cognitive effort than the holistic decision. Wilks and Zimbelman (2004) examined how the fraudtriangle decomposition affects overall fraud risk assessment. Instead of using long standardized fraud checklists, they recommended to split the risk assessment along the components of the fraud-triangle. They hypothesized that with focusing on seemingly unrelated list of fraud cues, auditors might lose sight of the overall fraud risk. Using the decomposition method in line with the fraud-triangle auditors not only free up resources of cognitive effort but auditors, before setting overall fraud risk level, are also enforced to focus better on the three components of the fraud risk. In their experiment they found that auditors' component assessments of opportunity and incentive risks are more sensitive to variations in those risks when they anticipate making these component assessments via a fraud triangle decomposition.

Hammersley et al. (2011) reported about an experiment testing how audit seniors respond to heightened fraud risk when 
constructing their audit plan. In the case study provided to the auditors, the authors manipulated the risk level by describing material weakness conditions in controls. The research proved that auditors assess higher fraud risk when material weakness information is present, but fail to produce a better quality audit plan. In contrast, the constructed audit plan was less efficient and of lower quality. Based on the study auditors, after assessing higher fraud risk, involved less efficient procedures by typically increasing the sample size instead of changing the nature of the audit program and/or involving more fraud specific procedures. The authors did not investigate training related questions, however they emphasized the need to reconsider and improve the auditors' professional trainings to assist them in fraud detection. They also identified two limitations of their study. First, auditors usually work in a team, so researches focusing on individual risk assessment and audit planning might not be representative. Secondly, the study failed to address the question why audit seniors draw up a lower quality audit plan if they assess higher fraud risk. Future research direction, to investigate the explanatory factors of the less efficient audit plan, was recommended by the authors.

Carpenter (2007) conducted an experiment to investigate the efficiency of team brainstorming in assessing fraud risk. 40 audit teams with three members each, representing all of the BIG 4 firms, participated in the study. She concluded that brainstorming sessions resulted in an overall loss of the individuals' ideas generated before the brainstorming session. However, it was also evidenced that the overall quality of the fraud ideas was improved after the session. As for the fraud risk, the results suggested that when fraud cues are present the audit team's fraud risk assessment after the brainstorming sessions is significantly higher than the assessed risk level of individual auditor's.

Seow (2009) tested the impact of technical knowledge and decision aid use on fraud risk assessment. It was found that decision aid use had a negative effect on high-knowledge participants while resulted in an improved performance in the case of low-knowledge students. The experiment was conducted in two groups where in one of the group's case text diagnostic and non-diagnostic fraud cues, taken from ISA 240, were disclosed. Other researches (Fukukawa et al., 2011; Favere-Marchesi, 2013) deal with the impact of fraud risk categorization on the risk assessment and audit planning decisions. Fukukawa et al. (2011) revealed that the auditors' grouping of individual client risks is basically in line with the categories provided by the prevailing auditing standards. Based on their findings, and on the fact that there is less or little guideline in the standards addressing the grouping of individual client risks, the authors urged the need to give training guidelines how auditors should draw up the groups. They also identified that the way to improve audit planning efficiency and effectiveness lays in the more efficient grouping of individual risks. However, Favere-Marchesi (2013) proved with their experiment involving 60 audit managers that auditors decomposing fraud risk assess a significantly different fraud risk than those who simply categorize fraud cues. The author also found that auditors decomposing fraud risk felt a higher need to modify audit plan and to enhance the extent of audit testing.

Several studies (e.g. Srivastava et al., 2011; Fukukawa and Mock, 2011) approach the fraud risk assessment from decision theory point of view. Fukukawa and Mock (2011) tested if assertion framing affects risk assessments and whether the effects hinge on risk assessment approach. In the experiment, assertion framing was manipulated by stating financial statement assertions in both positive and negative forms. The test indicated that when the belief-based assessments were transformed into probabilities, the difference was not significant. The authors could evidence significant assertion framing effects. As a final conclusion it can be stated that both the chosen risk measures and the way assertions are framed are proved to be important audit decisions and both have a large impact on the effectiveness and efficiency of an audit. The introduction of the Dempster-Shafter evidential reasoning theory (Srivastava et al., 2011) could be used with success in fraud risk assessment as the method can manage uncertainties related to audit risk, information security and information quality assessment. Authors also argue that instead of using a single audit risk model it is advised that auditors should assess separately the risk of errors, irregularities and management fraud.

A number of researchers (Loebbecke et al., 1989; Gold et al., 2010; Hoffman and Zimbelman, 2009; Asare and Wright, 2004; Hammersley et al., 2011; Hammersley, 2011) examined how frequently auditors meet with fraudulent financial statements, and all found that fraud is relatively rare. This raises the question how auditors gain most of their knowledge and ability to detect fraud and give the required responses. Hammersley (2011) stated that fraud related knowledge is gained mostly through training and not through experience, and this knowledge can be increased by higher problem solving ability and epistemic motivation. The aforementioned three factors (i.e. knowledge, problem solving ability and epistemic motivation) infiltrate into the process of audit planning, and explain how auditors modify their plans as a response to the assessed fraud risk.

\section{Research questions}

Taking into consideration the fundamental differences between two approaches (traditional vs. decomposition) elaborated previously, the decomposition fraud risk model is expected to result in a more precise risk assessment where auditors tend to be more sensitive, and their attention is notably directed to the successful identification and consideration of fraud cues. By using the decomposition approach, auditors might better identify the incentives/pressures management members might face to commit fraud. The decomposition model may also support auditors in revealing the weaknesses of internal control systems with higher success, and in more efficiently identifying 
the attitude through which perpetrators may rationalize their fraudulent acts. We set up a hypothesis in order to support these aforementioned ideas cited:

H1: With the assistance of the decomposition fraud risk assessment model, auditors' sensitivity to fraud cues between a high and low fraud risk condition is significantly greater than using the traditional audit risk model.

By assessing the fraud risk, auditors express their opinion, being partially objective or partially subjective, on the probability that financial statements are misstated due to fraud. Both fraud red flags, embedded in a scenario, and also individual sentiments are expressed in the level of the fraud risk assessed by a professional. We believe that all the consecutive actions made by the auditor, will be based on the outcome of this risk assessment, so most of our further hypotheses will examine how the responses given in the audit plan (audit procedures and time budget) correspond to the level of fraud risk assessed. However, in certain cases, mainly to conform to previous academic researches, we also examine the impact of the initial condition (applied risk assessment method, high or low risk scenario) on the audit planning decisions.

Nowadays a great variety of forensic services has been offered by consulting companies. The success in detecting fraud lies in a mixture of broad skills and knowledge (internal control, information technology, digital evidence recovery, auditing, psychology etc.), which are not always in the possession of auditors. Some researches (e.g. Asare and Wright, 2004) concluded that auditors are reluctant to consult with external fraud experts, while other studies evidenced that the propensity to consult with experts increases as the level of assessed fraud risk is getting higher. All of this gave us our next hypothesis:

$\mathrm{H} 2$ : The higher the assessed fraud risk is, the higher the auditors' propensity is to consult with external forensic experts.

Based on ISA 330, auditors shall determine overall responses to address the risks of material misstatement. Under circumstances where risk of material misstatement due to fraud is identified, the auditors' responses shall address the identified risks, and may include amendments into the nature, the extent and timing of audit procedures to be performed. Fraud effective tests are procedures, other than regularly conducted audit procedures, which specifically address the detection of material misstatement due to fraud. Several international studies evidenced (Zimbelman, 1997; Asare and Wright, 2004) that auditors are not successful in adjusting their audit programs to respond properly to the assessed level of fraud risk. The reason auditors fail to prepare a more effective audit program can be twofold. Either auditors do not have the knowledge of fraud specific procedures, or they simply do not feel the necessity to plan these procedures into the program. One might expect, as recommended by Srivastava et al. (2009), that by incorporating RSP into the fraud risk assessment model, the importance of proper fraud specific responses is more emphasized and highlighted, and the awareness of auditors is directed. However, we assume that by simply embedding RSP into the fraud risk assessment, auditors' attention will not significantly turn to fraud specific tests as they, either due to lack of proper training or experience, do not have the required knowledge.

H3: If auditors' assessed fraud risk is higher, they will not significantly modify the preliminary audit plan by including fraud effective tests compared to that condition when they assess lower fraud risk.

In a high risk condition where the assessed fraud risk is expected to be greater, auditors might assign more audit hours to perform the fraud effective tests and to extend procedures than previously budgeted. If auditors prepare a more effective audit plan including fraud related tests and procedures, then they will increase the budgeted hours of more experienced staff, so typically managers and partner hours will be enhanced. Our hypotheses:

H4: When auditors assess a higher fraud risk level, the total budgeted hours for the engagement will be significantly higher compared to the case when auditors assess a lower fraud risk level.

H5: When auditors assess a higher fraud risk level, the percentage of hours they assign to more experienced audit staff will be significantly higher than in a lower assessed fraud risk condition.

\section{Methodology}

The hypotheses are tested with four versions of a realistic case study ${ }^{2}$ ( 2 x 2 experiment) which vary in terms of the fraud risk assessment approach required (traditional vs. decomposition) and fraud risk setting (low risk vs. high risk). Participants received one type out of the four case versions. In the traditional method, auditors were expected to assess the components of the audit risk (i.e. inherent risk, control risk, and detection risk) with the traditional audit risk model required by the prevailing standards, and then to evaluate fraud risk separately. In the decomposition method besides the traditional audit risk assessment model participants were required to break down the fraud risk into sub elements of the fraud triangle; the risk of incentives or pressure, the risk of rationalization or attitude, and finally risk of opportunities to commit fraud. On the online questionnaire platform the RSP (Risk of special procedures) was automatically calculated with the assumption that the acceptable level of FR (Fraud Risk) is 0.05 . A lower than $1.00 \mathrm{RSP}$ indicated to auditors that they need to apply special forensic (fraud specific) procedures in order to keep FR at the desired 0.05 level.

2 This research is based on the case study (Precision Equipment Inc.) originally developed by Asare and Wright (2004) and used by several further fraud related studies (e.g. Hammersley et al., 2011; Mock et al., 2011 etc.). In the original case only minor adjustment and modifications were made in order to adopt it to the Hungarian conditions. 
Information provided to auditors differed to some extent whether low risk or high risk cases were delivered. In the low risk setting, management is compensated by a base salary and there do not exist extraordinary earnings targets to be achieved and also less details of the suspicious sales transaction are shared. In the high risk setting, management can get significant bonuses and share options if challenging targets are accomplished. In addition, a newly launched marketing campaign might have resulted in misstating revenues once distributors fail to increase sales despite the enhanced marketing efforts. Recognizing red flags (fraud cues) in the high risk setting was a key factor in the research as it directly relates to addressing the hypotheses.

As described in the introduction to the case study, participants were asked to finalize the audit programme for the revenue cycle of the designated client. Background information and key financial highlights (i.e. balance sheet, income statements, and key financial ratios) were provided, and a short industry analysis along with the firm's marketing strategy were also available. Based on previous years' audit experience, participants had information on the control environment and the revenue cycle.

In the first part of the case assignment, auditors were requested to complete the risk assessment by applying either the traditional or the decomposition approach.

As a second step, participants had to confirm/adjust the audit program for the revenue cycle. A preliminary substantive audit programme was offered, and participants had the opportunity to alter the programme in any way, even by deleting or adding new procedures or changing the extent of audit procedures, while keeping in mind the efficiency and the assessed level of risk.

In the third section, auditors were expected to update total budgeted hours (total 65 hours) by staff level (staff/senior/manager/partner hours) in order to reflect the proposed amendments in the audit procedures that address the perceived level of risk. On the other hand, participants were asked to express their opinion on the necessity of consulting a forensic expert to complete the audit plan on a 10 point Likert scale $(1=$ needless to consult, $5=$ moderate need to consult, $10=$ high need to consult).

In the final part, auditors responded to some fundamental demographic questions. The main issues encompassed auditing experience (BIG 4 or non-BIG 4, years of experience), position taken, educational background, membership in professional bodies, and prior knowledge of fraud triangle.

\section{Manipulation check}

In the survey, it was tested by a distinct question if the risk manipulation was successful or not. Respondents were asked to "Assess the level of fraud risk for the revenue cycle" on a 7 point Likert scale, where $1=$ low risk and $7=$ high risk. As it can be seen in Table 3 (Appendix), from the aspect of the overall fraud risk question, the manipulation was successful ( $p$ $=0.0186$ ) which means that the auditors encoded the two different risk settings as it was intended.

\section{Participants}

The participants voluntarily completed the case study online. They were instructed not to discuss their answers with colleagues, as individual judgement was of crucial importance. The Chamber of Hungarian Auditors assisted the research with informing its members about the online survey. Altogether 61 responses were collected electronically, out of which six were removed from the sample before further analysis due to either the incompleteness or inconsistency of answers, or even failure in the manipulation check.

Demographic information on the sample is detailed in Tables 1 and 2 . Table 1 demonstrates that $65 \%$ of participants (20 seniors, 15 partners, 1 executive director of audit firm) indicated high profile positions in which risk assessment and audit planning are core activities of their job. The risk assessment and the audit planning, tested by this study, are also performed by those auditors who do not work for audit firms as employees but run their own audit business individually (13\%, 7 persons). Subsequently, $78 \%$ of participants have profound experience in performing the tasks investigated through this research. As indication of successful randomization of the sample, statistical tests did not show significant differences in the demographic variables between the distinct survey conditions (low risk vs. high risk, decomposition vs. traditional).

Table 1 Current Position and Professional Background of the respondents $(\mathrm{N})$

\begin{tabular}{ll}
\hline Manager & $11(20 \%)$ \\
\hline Senior & $20(36 \%)$ \\
\hline Partner & $15(27)$ \\
\hline Other ${ }^{1}$ & $9(16 \%)$ \\
\hline Total & $\mathbf{5 5}(\mathbf{1 0 0} \%)$ \\
\hline ACCA student & $4(7 \%)$ \\
\hline ACCA member & $7(13 \%)$ \\
\hline MKVK ${ }^{2}$ student or mentoring phase & $5(9 \%)$ \\
\hline MKVK active member & $42(76 \%)$ \\
\hline MKVK inactive member & $2(36 \%)$ \\
\hline
\end{tabular}

Table 2 Other characteristics of the sample

\begin{tabular}{llll}
\hline & Mean (SD) & Min & Max \\
\hline Total audit experience (months) & $185.7(80.9)$ & 37 & 363 \\
$\begin{array}{l}\text { Experience with revenue } \\
\text { recognition (1-7) }\end{array}$ & $5.96(1.43)$ & 2 & 7 \\
\hline
\end{tabular}

Note: Experience with revenue recognition: 1 = no prior experience, $7=$ dealt with it very often

Participants had an average of 186 months of professional experience, with a standard deviation of 81 months. The indicated prior experience with the revenue cycle audit (mean 5.96 
on a 7 point Likert scale) also supports the idea that participants had the necessary skills and experience for answering the case assignment.

The IT background ensured randomly that the sample is consistent in terms of the four versions; 29 participants by the traditional approach (15 low risk, 14 high risk), 26 auditors by the decomposition approach (13 for both low and high risk).

\section{Results}

Performing the ANOVA (Table 4 in Appendix) analysis to understand the impact of the case version (high vs.. low risk scenario) and the applied risk assessment method (traditional vs. decomposition) on the level of fraud risk, we found that there is a significant main effect for risk version $(p=0.006217)$ and for the interaction between risk version and risk assessment approach $(p=0.00321)$. Single significant main effect could not be identified for the chosen risk assessment method ( $p=0.069598$ ), however, it is demonstrated in Fig. 2 (and Table 5 in Appendix) that with the application of the decomposition risk assessment method auditors could better differentiate between the high (mean: 0.488 ) and low (mean: 0.115) risk scenarios than applying the traditional one. We can conclude that the decomposition method of fraud risk assessment drew the attention of auditors to fraud cues more successfully than the traditional approach, thus enhanced the sensitivity to fraud risk. While in case of participants using the traditional approach, the lack of sensitivity to fraud risk can be identified. With all of previous $\mathrm{H} 1 \mathrm{can}$ be supported and justified.

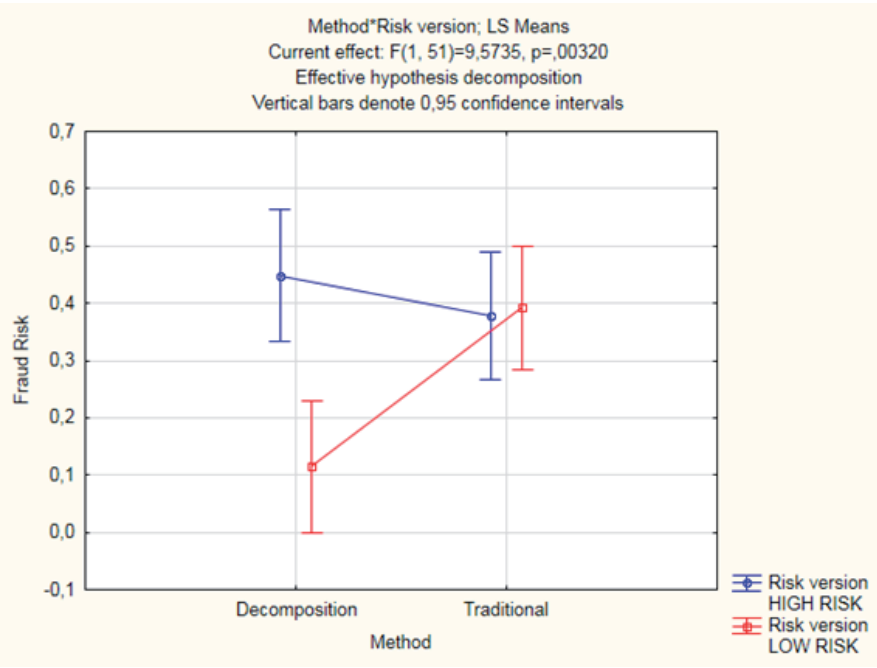

Fig. 2 Assessed Fraud Risk

Regarding the propensity of auditors to consult with external forensic experts, first the relationship between the level of fraud risk they assessed and the strength they felt (10 point Likert scale) the need to consult was tested. Figure 3 shows that a medium strong relationship $(\mathrm{r}=0.6059, \mathrm{r} 2=0.3671)$ can be identified between the fraud risk auditors assessed and the need they felt to consult with external forensic experts, supporting H2.
This means that the higher the fraud risk assessed by the auditors is, the higher need they feel to consult with an expert. As it was previously evidenced, the level of fraud risk is determined primarily by the risk version and the interaction between the risk version and the applied risk assessment method. We can assume that these two factors also have a significant main effect on auditors' intention to consult with experts. The ANOVA analysis in Table 6 in Appendix (and Fig. 4) shows that separately neither the risk version $(p=0.056512)$ nor the applied method (traditional vs. decomposition) $(\mathrm{p}=0.836907)$ has significant main effect on the auditor's propensity to consult with fraud experts, however their interaction is significant $(p=0.000750)$. This means that by applying the decomposition fraud risk assessment method, auditors can more effectively differentiate between the high and the low fraud risk setting, and as a consequence, they can better adjust their consideration whether to consult with external fraud expert. The highest need to consult with external forensic experts (mean 5.77, SD 2.28) was revealed in the high risk setting with the decomposition approach.

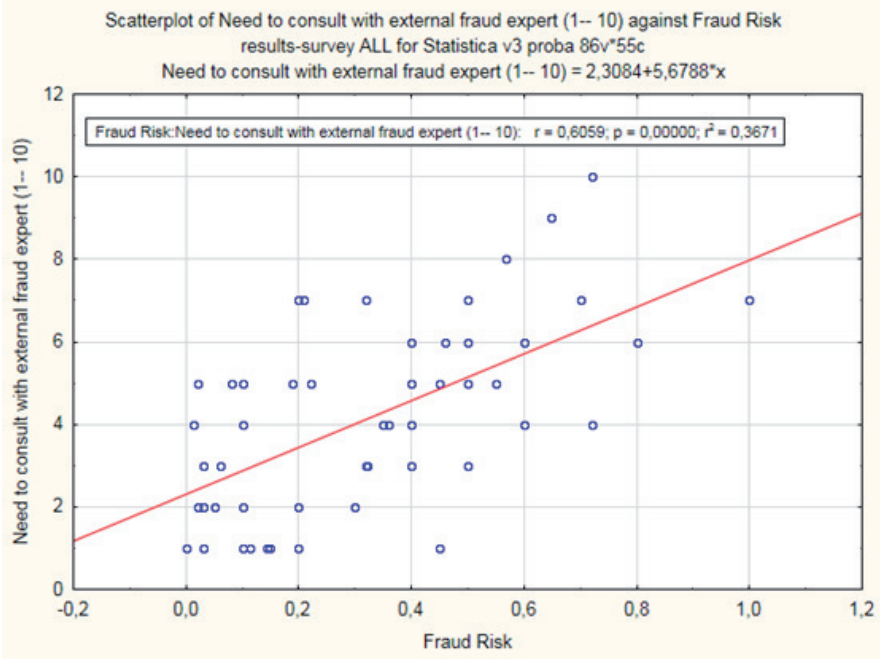

Fig. 3 The relationship between the Assessed Fraud Risk and Need to Consult with external fraud expert

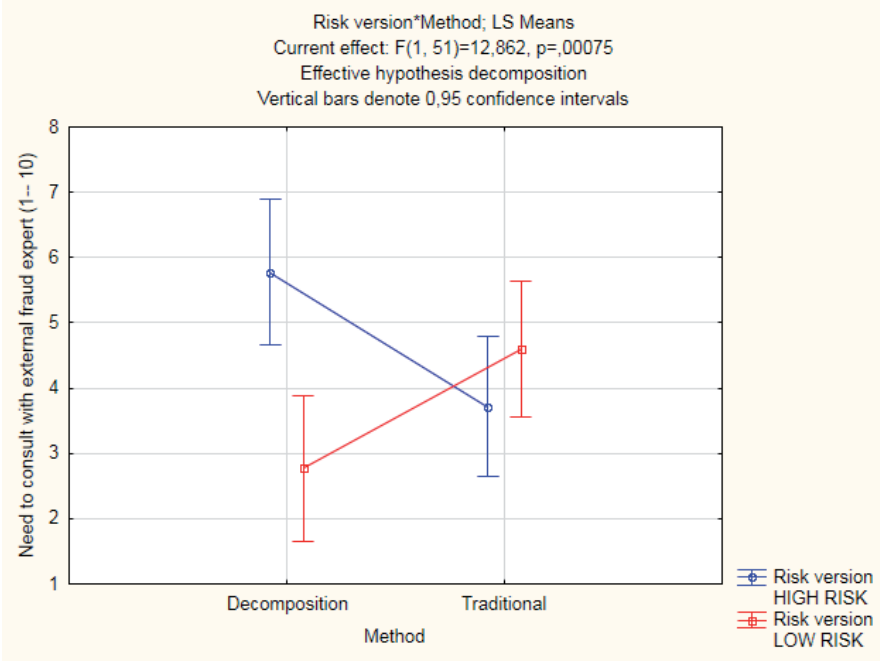

Fig. 4 Need to consult with external fraud expert 
In order to test the auditors' responses to a higher assessed fraud risk level from the standpoint of the audit procedures, the modified audit plan responses received from participants were split into two categories. Responses with an assessed fraud risk below 0.28 were grouped together into Category "low", while the responses above 0.28 fraud risk level were clustered to Category "high". As standard distribution for the assessed fraud risk cases could not be observed from the sample, the separation between low and high fraud risk responses was performed on the basis of Fig. 5, which shows a well-identifiable gap in the responses at 0.28 assessed level of fraud risk. Examining the audit planning decisions (Table 8 in Appendix) one can find that auditors primarily chose either to perform the standard procedure or they increase sample size. Performing the Chi-Square test for the two most commonly indicated answers we can see that the fraud risk level has significant impact on neither of the most frequently given answers ("Perform standard procedure": Chi-Sq $=8.251, \mathrm{DF}=12, \mathrm{P}$-Value $=0.765$; "Increase sample size": Chi-Sq $=9.951, \mathrm{DF}=12, \mathrm{P}-$ Value $=0.62$ ).

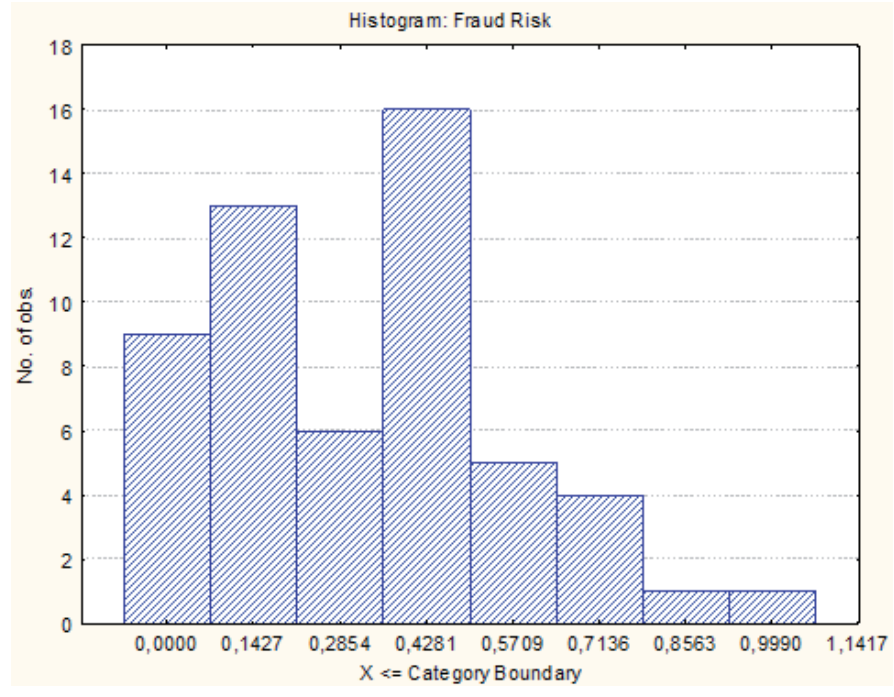

Fig. 5 Observed fraud risk level

For testing $\mathrm{H} 4$ and H5, first a Sign test for median was performed (Table 9 in Appendix) which indicates that auditors prepared a significantly different time budget compared to the preliminary time budget given. The Mann-Whitney $U$ test (Table 10 in Appendix) performed indicates that the fraud risk category ("high" and "low") has a significant main effect both on the total hours budgeted $(\mathrm{p}=0.015633)$ and on the manager hours budgeted $(\mathrm{p}=0.003273)$. We can conclude that auditors not only give a significantly different total hours staffing compared to the preliminary budget but also they increase manager hours most typically, thus H4 and H5 are supported. However, consolidating the results of the time budget and the audit plan examinations it turns out that auditors, as a response to higher assessed fraud risk, routinely increase sample size or perform standard procedure for which they typically budget higher manager hours. Using more experienced staff for doing more from the same procedures is not effective, and could make an audit engagement excessively expensive.

\section{Conclusion}

Our study examined two crucial steps of the audit process; the fraud risk assessment and the audit program planning tasks. Fraud, its detection and prevention have not just been exciting current issues, but also their academic investigation has an extended background. The contribution of this research to the academic literature and to the auditing profession itself is twofold. First, our fundamental objective was to conduct a test in Hungary which delivers answers to a commonly tackled questions in the international literature. Secondly, by contrasting our results to previous researches, we intended to give a hand to the development of external audit profession at national level.

One of our major findings is that the application of the decomposition fraud risk assessment method enhanced the sensitivity of auditors to fraud cues, and as a consequence, they could better differentiate between a high and low fraud risk scenario, while by using the traditional approach they failed to make a significant distinction. The results suggest that the higher the assessed fraud risk is, the more likely auditors will feel the need to consult with external forensic experts is. Examining audit planning decisions the study revealed that decomposition fraud risk assessment improved the ability to identify high risk engagements, however, does not result in an audit plan of higher quality. Auditors generally either perform the standard procedure or increase sample sizes, but do not imply remarkable fraud effective tests. From the aspect of the time budget setting, higher assessed fraud risk usually results in higher total budgeted hours, and most typically auditors increase the budgeted hours for more experienced staff (managers). This might result in an ineffective audit program, where auditors use managers' capacity to cope with increased sample sizes. The failure in giving proper responses to higher fraud risk might arise from two sources. By incorporating the risk of special procedures into the fraud risk assessment model and evaluating the results, we can conclude that the shortage of knowledge is a more significant factor than the lack of the auditors' attention towards the necessity of these procedures. As the occurrence of fraud is quite rare in real life, the most effective way of improving the auditors' knowledge can be overcome by trainings and professional education.

The results could also have a primary impact on our professional practice, as the obvious advantages of the decomposition method might result in its widespread practical implementation. The fact that auditors proved to be unable to give proper responses to a higher assessed fraud risk, might urge the need to make the necessary modifications in the field of professional trainings as well. In order to support the latter idea, further research directions should investigate the relationship between different demographical aspects of participants, such us previous professional experience and training, and the quality of the audit plan responses give. 


\section{Acknowledgement}

Special thanks to Professor Theodore J. Mock at the University of California and the University of Maastricht for his valuable remarks and guidance.

The help of the Chamber of Hungarian Auditors is highly appreciated. The authors gratefully acknowledge the assistance of all participants.

\section{References}

American Institute of Certified Public Accountants (2014) Substantive differences between the International Standards on Auditing and Generally Accepted Auditing Standards. [Online]. Available from: www.aicpa.org [Accessed: 26th June 2015]

American Institute of Certified Public Accountants (2011) The AICPA's guide to clarified and converged standards for auditing and quality control. [Online]. Available from: www.aicpa.org [Accessed: 26th June 2015]

Auditing Standards Board. Clarified Statements on Auditing Standards. [Online]. Available from: www.aicpa.org [Accessed: 5th July 2015]

Asare, S. K., Wright, A. M. (2004) The effectiveness of Alternative Risk Assessment and Program Planning Tools in a Fraud Setting. Contemporary Accounting Research. 21(2), pp. 325-352. DOI: 10.1506/1201-7fum-fpcb-7be2

Carpenter, T. D. (2007) Audit Team Brainstorming, Fraud Risk Identification, and Fraud Risk Assessment: Implication of SAS No. 99. The Accounting Review. 82(5), pp. 1119-1140. DOI: 10.2308/accr.2007.82.5.1119

Cressey, D. R. (1973) Other People's Money. Patterson Smith, Montclair.

Favere-Marchesi, M. (2013) Effects of Decomposition and Categorization on Fraud-Risk Assessments. Auditing: A Journal of Practice \& Theory. 32(4), pp. 201-219. DOI: 10.2308/ajpt-50528

Fukukawa, H., Mock, T. J., Wright, A. (2011) Client Risk Factors and Audit Resource Allocation Decisions. ABACUS: A Journal of Accounting, Finance and Business Studies. 47(1), pp. 85-108. DOI: $10.1111 / \mathrm{j} .1467-6281.2011 .00332 . x$

Fukukawa, H., Mock, T. J. (2011) Audit Risk Assessment Using Belief Vs. Probability. Auditing: A Journal of Practice \& Theory. 30(1), pp. 75-99. DOI: 10.2308/aud.2011.30.1.75

Gold, A. W., Knechel, W. R., Wallage, P. (2010) The effect of audit standards on fraud consultation and auditor judgement. Working Paper, Erasmus University.
Hammersley, J. S., Johnstone, K. M., Kadous, K. (2011) How Do Audit Seniors Respond to Heightened Fraud Risk?. Auditing: A journal of Practice and Theory. 30(3), pp. 81-101. DOI: 10.2308/ajpt-10110

Hammersley, J. S. (2011) A Review Model of Auditor Judgements in FraudRelated Planning Tasks. Auditing: A Journal of Practice \& Theory. 30(4), pp. 101-128. DOI: 10.2139/ssrn. 1758097

Hoffman, V. B., Zimbelman, M. F. (2009) Do strategic reasoning and brainstorming help auditors change their standard audit procedures in response to fraud risk? The Accounting Review. 85(3), pp. 911-935. DOI: 10.2308 /accr.2009.84.3.811

International Auditing and Assurance Standards Board. International Standards on Auditing. [Online]. Available from: www.ifac.org [Accessed: 5th July 2015]

Knapp, C. A., Knapp. M. C. (2001) The effects of experience and explicit fraud risk assessment in detecting fraud with analytical procedures. Accounting, Organizations and Society. 26, pp. 25-37. DOI: $10.1016 / \mathrm{s} 0361-3682(00) 00005-2$

Loebbecke, J. K., Eining M. M., Willingham M. F. (1989) Auditors' experience with material irregularities: Frequency, nature and detectability. Auditing: A Journal of Practice and Theory. 9(1), pp. 1-28.

Seow, J-L. (2009) Cue usage in financial statement fraud risk assessments: effects of technical knowledge and decision aid use. Accounting and Finance. 49, pp. 183-205. DOI: 10.1111/j.1467-629x.2008.00268.x

Shelton, S. W., Whittington O. R., Landsittel, D. (2001) Auditing firms' fraud risk assessment practices. Accounting Horizons. 15(1), pp. 19-33. DOI: $10.2308 /$ acch.2001.15.1.19

Srivastava, R. P., Mock, T. J., Gao, L. (2011) The Dempster-Shafter Theory: An Introduction and Fraud Risk Assessment Illustration. Australian Accounting Review. 21(3), pp. 282-291. DOI: $10.1111 /$ j.1835-2561.2011.00135.x

Srivastava, R. P., Mock, T. J., Turner, J. L. (2009) Bayesian Fraud Risk Formula for Financial Statement Audits. Abacus. 45(1), pp. 66-87. DOI: $10.1111 / j .1467-6281.2009 .00278 . x$

Wilks, T. J., Zimbelman, M. F. (2004) Decomposition of fraud-risk assessments and auditors' sensitivity to fraud cues. Contemporary Accounting Research. 21(3), pp. 719-745. DOI: 10.1506/hgxp-4dbh-59d1-3fhj

Zimbelman, M.F. (1997) The effects of SAS No. 82 on Auditors' Attention to Fraud Risk Factors and Audit Planning Decisions. Journal of Accounting Research. 35, pp. 75-97. DOI: 10.2307/2491454

\section{Appendix}

Table 3 Manipulation check

\begin{tabular}{|c|c|c|c|c|c|c|c|c|c|c|c|}
\hline \multirow[b]{2}{*}{ Variables } & \multicolumn{11}{|c|}{$\begin{array}{l}\text { T-test; Grouping: Risk version } \\
\text { Group 1: HIGH RISK Group 2: LOW RISK }\end{array}$} \\
\hline & $\begin{array}{l}\text { Mean } \\
\text { High } \\
\text { Risk }\end{array}$ & $\begin{array}{c}\text { Mean } \\
\text { Low } \\
\text { Risk }\end{array}$ & t-Value & $\mathrm{df}$ & $\mathrm{p}$ & $\begin{array}{l}\text { Valid N High } \\
\quad \text { Risk }\end{array}$ & $\begin{array}{l}\text { Valid N } \\
\text { Low Risk }\end{array}$ & $\begin{array}{l}\text { Std.Dev. } \\
\text { High Risk }\end{array}$ & $\begin{array}{l}\text { Std.Dev. } \\
\text { Low Risk }\end{array}$ & $\begin{array}{c}\text { F-ratio } \\
\text { Variances }\end{array}$ & $\begin{array}{c}\mathrm{p} \\
\text { Variances }\end{array}$ \\
\hline $\begin{array}{l}\text { Overall } \\
\text { Fraud Risk }\end{array}$ & 4.37 & 3.36 & 2.429 & 53 & 0.0186 & 27 & 28 & 1.6443 & 1.4457 & 1.2937 & 0.5102 \\
\hline
\end{tabular}


Table 4 Assessed Fraud Risk - ANOVA results

\begin{tabular}{lccccc}
\hline & \multicolumn{5}{l}{$\begin{array}{l}\text { Univariate Tests of Significance for Fraud Risk } \\
\text { Sigma-restricted parameterization } \\
\text { Effective hypothesis decomposition }\end{array}$} \\
\hline Effect & $\mathrm{SS}$ & Degr. of Freedom & Mean Square & $\mathrm{F}$ & $\mathrm{p}$ \\
Intercept & 6.090096 & 1 & 6.090096 & 141.5304 & 0.000000 \\
Method & 0.147830 & 1 & 0.147830 & 3.4355 & 0.069598 \\
Risk version & 0.350617 & 1 & 0.350617 & 8.1481 & 0.006217 \\
Method*Risk version & 0.411953 & 1 & 0.411953 & 9.5735 & 0.003201 \\
Error & 2.194546 & 51 & 0.043030 & & \\
\hline
\end{tabular}

Note: Method = traditional fraud risk assessment vs. decomposition fraud risk assessment; Risk version= low vs. high risk scenario

Table 5 Descriptive statistics - Assessed fraud risk (Mean (SD) [N])

\begin{tabular}{lccc}
\hline Method & Low Risk Scenario & High Risk Scenario & Total \\
\hline Traditional & $0.392(0.271)[15]$ & $0.379(0.148)[14]$ & $0.386(0.217)[29]$ \\
Decomposition & $0.115(0.192)[13]$ & $0.488(0.190)[13]$ & $0.281(0.253)[26]$ \\
Total & $0.263(0.273)[28]$ & $0.412(0.167)[27]$ & $0.336(0.238)[55]$ \\
\hline
\end{tabular}

Note: Dependent variable - fraud risk assessment $0.00-1.00$ (probability of fraud, where $0=$ no chance of occurrence and $1.00=100 \%$ chance of occurrence)

Table 6 Need to consult with external fraud expert - ANOVA results

\begin{tabular}{|c|c|c|c|c|c|}
\hline \multirow[b]{2}{*}{ Effect } & \multicolumn{5}{|c|}{$\begin{array}{l}\text { Univariate Tests of Significance for Need to consult with external fraud expert }(1-10) \\
\text { Sigma-restricted parameterization } \\
\text { Effective hypothesis decomposition }\end{array}$} \\
\hline & SS & Degr. of Freedom & Mean Square & $\mathrm{F}$ & $\mathrm{p}$ \\
\hline Intercept & 972.8497 & 1 & 972.8497 & 241.9404 & 0.000000 \\
\hline Risk version & 15.3120 & 1 & 15.3120 & 3.8080 & 0.056512 \\
\hline Method & 0.1721 & 1 & 0.1721 & 0.0428 & 0.836907 \\
\hline Risk version*Method & 51.7185 & 1 & 51.7185 & 12.8620 & 0.000750 \\
\hline Error & 205.0725 & 51 & 4.0210 & & \\
\hline
\end{tabular}

Note: Method = traditional fraud risk assessment vs. decomposition fraud risk assessment; Risk version $=$ low vs. high risk scenario

Table 7 Descriptive statistics - Need to consult with external fraud expert (1 - 10) (Mean (SD) [N])

\begin{tabular}{lccc}
\hline Method & Low Risk Scenario & High Risk Scenario & Total \\
\hline Traditional & $4,600(1.957)[15]$ & $3.714(1.939)[14]$ & $4.172(1.965)[29]$ \\
Decomposition & $2.769(1,833)[13]$ & $5,769(2,279)[13]$ & $4.269(2.539)[26]$ \\
Total & $3.750(2.084)[28]$ & $4.704(2.317)[27]$ & $4.218(2.234)[55]$ \\
\hline
\end{tabular}

Note: Dependent variable - Need to consult with external fraud expert $1-10$ 
Table 8 Descriptive statistics - Distribution of auditors' answers regarding their audit planning decision

\begin{tabular}{|c|c|c|c|c|c|c|c|c|}
\hline & \multicolumn{2}{|c|}{$\begin{array}{l}\text { Omit procedure / not } \\
\text { meaningful }\end{array}$} & \multicolumn{2}{|c|}{ Perform standard procedure } & \multicolumn{2}{|c|}{ Increase sample size } & \multicolumn{2}{|c|}{$\begin{array}{c}\text { Other modifications in the } \\
\text { audit program }\end{array}$} \\
\hline & „low” risk & „high” risk & „low” risk & „high” risk & „low” risk & „high” risk & „low” risk & „high” risk \\
\hline AP1 & 4.35 & 0.00 & 73.91 & 71.88 & 21.74 & 15.63 & 0.00 & 12.50 \\
\hline AP2 & 0.00 & 0.00 & 60.87 & 46.88 & 34.78 & 46.88 & 4.35 & 6.25 \\
\hline AP3 & 4.35 & 0.00 & 39.13 & 34.38 & 47.83 & 56.25 & 8.70 & 9.38 \\
\hline AP4 & 0.00 & 0.00 & 39.13 & 25.00 & 47.83 & 62.50 & 13.04 & 12.50 \\
\hline AP5 & 0.00 & 0.00 & 69.57 & 43.75 & 30.43 & 46.88 & 0.00 & 9.38 \\
\hline AP6 & 8.70 & 9.38 & 56.52 & 53.13 & 30.43 & 34.38 & 4.35 & 3.13 \\
\hline AP7 & 8.70 & 0.00 & 52.17 & 25.00 & 34.78 & 62.50 & 4.35 & 12.50 \\
\hline AP8 & 26.09 & 9.38 & 69.57 & 50.00 & 4.35 & 31.25 & 0.00 & 9.38 \\
\hline AP9 & 30.43 & 6.25 & 52.17 & 68.75 & 13.04 & 25.00 & 4.35 & 0.00 \\
\hline AP10 & 8.70 & 18.75 & 69.57 & 40.63 & 21.74 & 28.13 & 0.00 & 12.50 \\
\hline AP11 & 0.00 & 0.00 & 52.17 & 75.00 & 47.83 & 25.00 & 0.00 & 0.00 \\
\hline AP12 & 4.35 & 3.13 & 82.61 & 81.25 & 8.70 & 15.63 & 4.35 & 0.00 \\
\hline AP13 & 17.39 & 6.25 & 52.17 & 46.88 & 26.09 & 40.63 & 4.35 & 6.25 \\
\hline
\end{tabular}

Table 9 Sign test for median - Time budget

\begin{tabular}{lccccccc}
\hline & \multicolumn{7}{c}{ Sign Test of median $=\mathbf{0 . 0 0 0 0 0}$ versus $>\mathbf{0 . 0 0 0 0 0}$} \\
\cline { 2 - 8 } & $\mathbf{N}$ & $\mathbf{N}^{*}$ & Below & Equal & Above & $\mathbf{p}$ & median \\
\hline Assistant hours & 54 & 1 & 8 & 20 & 26 & 0.0015 & 0.0000 \\
Senior hours & 54 & 1 & 8 & 12 & 34 & 0.0000 & 5.0000 \\
Manager hours & 54 & 1 & 6 & 22 & 26 & 0.0003 & 0.0000 \\
Partner hours & 54 & 1 & 3 & 16 & 35 & 0.0000 & 2.0000 \\
Total hours & 54 & 1 & 5 & 5 & 44 & 0.0000 & 14.5000 \\
\hline
\end{tabular}

Table 10 Time budget modification responses to the assessed fraud risk

\begin{tabular}{|c|c|c|c|c|c|c|c|c|c|c|}
\hline \multirow{2}{*}{ Variables } & \multicolumn{10}{|c|}{$\begin{array}{l}\text { Mann-Whitney U Test (w/ continuity correction) } \\
\text { By variable Kock_kat Marked tests are significant at } p<, 05000\end{array}$} \\
\hline & $\begin{array}{c}\text { Rank } \\
\text { Sum high }\end{array}$ & $\begin{array}{c}\text { Rank } \\
\text { Sum low }\end{array}$ & $\mathbf{U}$ & $\mathbf{Z}$ & p-value & $\begin{array}{c}\mathrm{Z} \\
\text { adjusted }\end{array}$ & p value & $\begin{array}{c}\text { Valid N } \\
\text { high }\end{array}$ & $\begin{array}{c}\text { Valid } N \\
\text { low }\end{array}$ & $\begin{array}{l}2 * 1 \text { sided } \\
\text { exact p }\end{array}$ \\
\hline Assistant Hours & 951.0 & 589.0 & 313.0 & 0.9299 & 0.352404 & 0.964163 & 0.334965 & 32 & 23 & 0.355370 \\
\hline Senior Hours & 973.0 & 567.0 & 291.0 & 1.3053 & 0.191783 & 1.339110 & 0.180536 & 32 & 23 & 0.193459 \\
\hline Manager Hours & 1065.5 & 474.5 & 198.5 & 2.8837 & 0.003931 & 2.990834 & 0.002782 & 32 & 23 & 0.003273 \\
\hline Partner Hours & 983.0 & 557.0 & 281.0 & 1.4759 & 0.139956 & 1.509977 & 0.131050 & 32 & 23 & 0.140908 \\
\hline Total Hours & 1037.0 & 503.0 & 227.0 & 2.3974 & 0.016514 & 2.408555 & 0.016016 & 32 & 23 & 0.015633 \\
\hline
\end{tabular}

